\title{
Exploring the World of Knowledge Management: Agreements \& Disagreements in the Research Community
}

\author{
DR. KOSTAS METAXIOTIS, KOSTAS ERGAZAKIS, PROF. JOHN PSARRAS \\ School of Electrical \& Computer Engineering \\ National Technical University of Athens \\ 9, Iroon Polytechniou str. Zografou 15773, Athens \\ GREECE
}

\begin{abstract}
Over the past several years there have been intensive discussions about the importance of Knowledge Management (KM) within our society. As we are moving into an era of "knowledge capitalism", the management of knowledge is promoted as an important and necessary factor for organizational survival and maintenance of competitive strength. During the last 15 years, KM has changed from one generation to the next through constant improvements and new perspectives. A myriad of researchers have presented methodologies, frameworks, technologies and have discussed various KM theoretical and practical issues. However, KM still needs extensive development - it is in its infancy. This paper aims to explore the world of KM in a different way; to review the current status quo and analyze the main agreements and disagreements among researchers and practitioners in order to highlight the key issues which need to be further researched. The distinguishing feature of this study is that it emphasizes placing $\mathrm{KM}$ in a broader context of researchers/practitioners' discussions so that the key issues can better be recognized and understood.
\end{abstract}

Key-Words: - Knowledge Management, Frameworks, Knowledge

\section{Introduction}

There is growing recognition in the business community about the importance of knowledge as a critical resource for organizations [1-3]. The new, knowledge-based economy places great importance on the diffusion and use of information and knowledge, as well as its creation. In this new economy, individuals and companies are obliged to focus on maintaining and enhancing their knowledge capital in order to innovate, and their ability to learn, adapt and change becomes a core competency for survival. KM has gained a great deal of attention from both the academic and practitioners' point of view [4-6]. The famous statement "If only we knew what we know..." has prompted the idea of capturing, sharing and applying knowledge all over the organization. Although there is recognition that knowledge is a key business asset, organizations are still in the early stages of understanding the implications of $\mathrm{KM}$, and $\mathrm{KM}$ is slowly becoming an integral business function for them. Current research [7-10] has shown that a knowledge-based company possesses information and knowledge that confer a special advantage, allowing it to maneuver with intelligence, creativity, and occasionally, cunning. It is well prepared to sustain its growth and develop in a dynamic environment. By marshalling the skills and expertise of its members, it is able to engage in continuous learning and innovation. A myriad of researchers and practitioners have presented $\mathrm{KM}$ methodologies, frameworks, and technologies and have discussed various KM theoretical and practical issues. Some 15 years after its introduction, KM is now a keyword in bibliographic databases and forms the conceptual nucleus of a developing literature [11-12]. The aim of this paper is to explore the world of $\mathrm{KM}$ in a different way, by reviewing the current status quo and analyzing the main agreements and disagreements among researchers and practitioners in order to highlight the key issues, which need to be further researched. Since it is not feasible to cover all the literature, our main purpose is not so much to summarize but to recognize the $\mathrm{KM}$ issues on which researchers/practitioners agree or disagree and draw some conclusions about directions for future research, avoiding KM fields that have already been over-researched (researchers have come to specific agreements and conclusions). This study seeks to contribute to the deeper understanding of $\mathrm{KM}$ complexity and orientations. We begin with background discussion about the management of knowledge, followed by a brief presentation of important KM aspects. Next, a critical examination of main agreements and disagreements in the research community is presented. Finally, conclusions and suggestions of future directions for further research are provided. 


\section{A Journey to KM History}

Knowledge management has its origins in a number of related business improvement areas, such as total quality management (TQM), business process reengineering (BPR), information systems (IS) and human resource management (HR). It emerged on the maps of strategy consultants and conference organizers in the beginning of 1990's, although the knowledge debate had started much earlier [13-14]. In 1965 Marshall [15] argued that capital consists, in the greater part, of knowledge and organization and that knowledge is the most powerful engine of production organizations increasingly focused on management, while Kuhn [16] stressed that the knowledge embraced by a field of endeavor is "...intrinsically the common property of a group or else nothing at all". In 1972 Habermas [17] argued that knowledge does not exist as some abstract entity, but is the product of intentional and, sometimes, unconscious human activity.

Historically, we can distinguish three generations of knowledge management. The period 1990-1995 can be called as the first generation of KM. During this generation of $\mathrm{KM}$, many initiatives focused on defining knowledge management, investigating the potential benefits of $\mathrm{KM}$ for businesses, and designing specific KM projects [18-21]. Also, progress on artificial intelligence influenced research on $\mathrm{KM}$, mainly in the direction of knowledge representation and storing [22-24]. The second generation of KM started to emerge around 1996 with many corporations setting up new jobs for KM specialists and "chief knowledge officers". The different sources of KM became combined and also quickly absorbed to everyday organizational discourse. During this generation, KM research touched knowledge definitional issues (Figure 1), business philosophies [26-28], systems [29-31], frameworks [32-35], operations and practices [3637], advanced technologies [38-41].

Fig. 1:A taxonomy of knowledge adopted by Fowler [25]

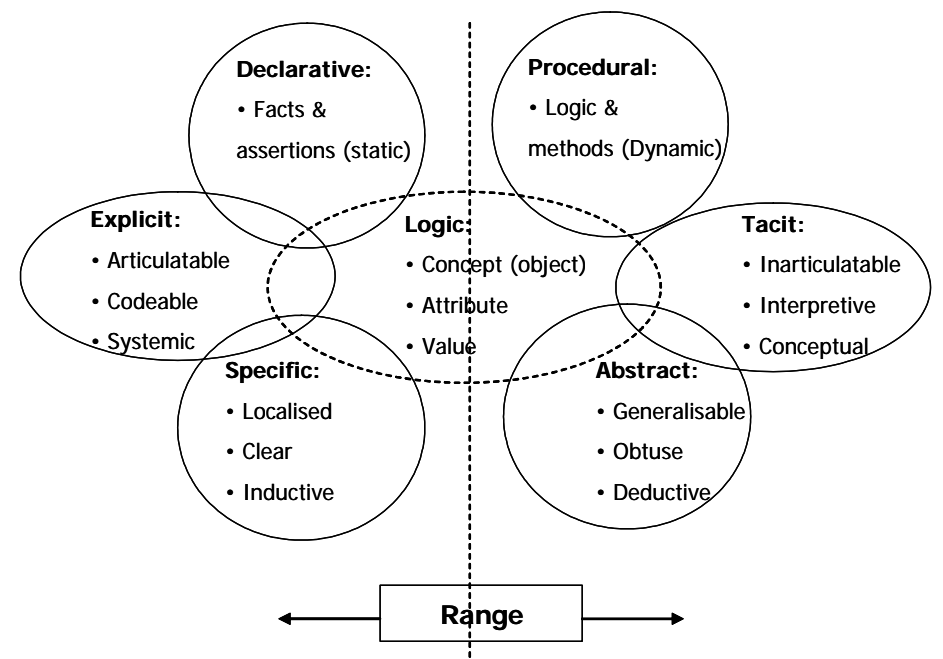

On a more practical level, second-generation $\mathrm{KM}$ emphasized that $\mathrm{KM}$ is about systemic organizational change where management practices, measurement systems, tools and content management needed to be co-developed. Resulting from new insights and practices, a new, third generation of $\mathrm{KM}$ is now emerging with new methods and results. According to Wiig [42], "one difference from the earlier KM generations is the degree to which the third generation is integrated with the enterprise's philosophy, strategy, goals, practices, systems and procedures and how it becomes part of each employee's daily work-life and motivation....". The third generation seems to emphasize the link between knowing and action [43]. All knowledge is inherently social and cultural, and organizational knowledge can only be realized through change in organizational activity and practice. Table 1 presents some of the most important research contributions to the field of KM, which are considered today as reference points for further research.

\section{Table 1: A sample of important research contributions to KM}

\section{KM theme}

Distinction between

explicit and tacit

knowledge

"Taxonomic" knowledge

$\mathrm{KM}$ foundations

KM frameworks

Successful KM projects

$\mathrm{KM}$ and $\mathrm{AI}$

$\mathrm{KM}$ and decision support

KM surveys

KM software tools

KM and SMEs

$\mathrm{KM}$ and higher education

KM standardization
Authors

Polyani 1966 [44], Nonaka et al. 1995 [45]

Tsoukas 1996 [46]

Wiig 1993 [21], Liebowitz 1999 [47]

Holsapple et al. 1997 [32], Rubenstain et al. 2001 [48]

Davenport et al. 1998 [49]

Fowler 2000 [25], Liebowitz 2001 [50]

Courtney 2001 [51], Bolloju et al. 2002 [52]

Liao 2003 [40], Kakabadse et al. 2003 [53]

Tyndale 2002 [54]

McAdam et al. 2001 [28], Wickert et al. 2001 [55]

Rowley 2000 [56], Metaxiotis et al. 2003 [57]

Weber et al. 2002 [58] 
In the next sections, this paper presents a critical examination of main agreements and disagreements in the KM research community, as they are reported in the literature.

\section{Main Agreements}

\subsection{Definition of KM}

The complexity behind defining knowledge management is partially caused by the challenges in identifying knowledge itself. Many varying definitions of KM appear in the literature; among others we can mention the following:

"Knowledge management is...knowledge creation, which is followed by knowledge interpretation, knowledge dissemination and use, and knowledge retention and refinement (De Jarnett 1996, [59]).

Knowledge management is the process of critically managing knowledge to meet existing needs, to identify and exploit existing and acquired knowledge assets and to develop new opportunities (Quintas et al. 1997, [60]).

The following definition seems to represent the general agreement of the researchers on $\mathrm{KM}$ definition:

"Knowledge management is concerned with the exploitation and development of the knowledge assets of an organization with a view to furthering the organisation's objectives. The knowledge to be managed includes both explicit, documented knowledge, and tacit, subjective knowledge..." (Davenport et al. 1998, [7]).

\subsection{Primary objectives of KM}

Reviewing the literature, what is apparent is that there is general agreement that the primary objectives of $\mathrm{KM}$ are to identify and leverage the collective knowledge in an organization to achieve the overriding goal of helping organizations compete and survive [61]. These objectives are somewhat distinct from the objectives in information management; unfortunately this distinction is not a simple one, especially since success in KM depends on successful information management in that the latter is an essential building block. In addition, there appears to be a general agreement that a knowledge design process is required to identify and leverage this collective knowledge.

\subsection{KM benefits for modern organizations}

It is agreed that successful companies are those that create new knowledge, disseminate it widely throughout the organization and quickly embody it into new technologies and products; this process fuels innovation and develops lasting competitive advantage. Indeed, in a top-line finding of a survey of Ernst \& Young [62], executives see innovation as the greatest payoff from KM, even though $\mathrm{KM}$ efforts have so far concentrated on achieving productivity gains. Henry et al. [63] link innovation to "new knowledge" or new constructed knowledge by showing how tacit knowledge can become explicit knowledge. Other benefits include increased organizational learning, improved intellectual asset management, increased operational efficiency, time-to-market improvement, and continuous improvement [64].

\subsection{Categorization of KM projects}

Davenport et al. [49] managed to categorize KM projects - and accepted by the research community on the basis of the projects' objectives. They identified four broad types of $\mathrm{KM}$ project objectives:

1. To create knowledge repositories, which store both knowledge and information, often in documentary form. Repositories can fall into three categories:

- Those which include external knowledge, such as competitive intelligence

- Those that include structured internal knowledge, such as research reports and product oriented marketing material as techniques and methods

- Those that embrace informal, internal or tacit knowledge, such as discussion databases that store "know how".

2. To improve knowledge access, or to provide access to knowledge or to facilitate its transfer amongst individuals; here the emphasis is on connectivity, access and transfer, and technologies such as video conferencing systems, sharing tools and telecommunications networks are central.

3. To enhance he knowledge environment, so that the environment is conducive to more effective knowledge creation, transfer and use. This involves tackling organizational norms and values as they relate to knowledge.

4. To manage knowledge as an asset, and to recognize the value of knowledge to an 
organization. Assets, such as technologies that are sold under license or have potential value, customer databases and detailed parts catalogues are typical of companies' intangible assets to which value can be assigned.

\subsection{Factors that influence KM}

In literature, it is agreed that a broad range of factors can influence the success of KM initiatives; the following factors presented by Holsapple et al. [65] represent this general agreement of the researchers:

- Culture

- Leadership

- Technology

- Organizational adjustments

- Employee motivation

- External factors

In a previous study made by Holsapple [66], the factors were organized into three categories:
$>$ Managerial influences
$>$ Resource influences
$>$ Environmental influences.

\subsection{Single- and double-loop learning in $\mathrm{KM}$}

There is a body of literature on KM dealing with the issue of learning; in general, learning has been identified as an outcome of KM activities [67-68]. Argyris et al. [69] distinguish between double- and single-loop learning where single loop learning is that which organizations do for corrective purposes (incremental changes); double-loop is more generative and involves learning on a more fundamental level where basic assumptions are changed. Researchers agree that, although a complete learning mode should include both singleand double-loop learning, double-loop learning is the type that is lucking in existing KM frameworks.

\section{Main Disagreements}

\subsection{KM frameworks}

In general, a framework is a holistic and concise description of the major elements, concepts and principles of a particular domain. The main aim of a framework is to explain the domain and define a standardized schema of its core content as a reference for future design implementations. A KM framework names the major KM elements, their relationships and the principles that define the way in which these elements interact. In this way, it provides the reference for decisions about the implementation and application of a KM system / project within an organization or an enterprise. The KM frameworks can be classified as either prescriptive, descriptive or a combination of the two [70]. Prescriptive frameworks provide general directions about the types of KM procedures, without providing specific details of how those procedures can / should be accomplished, while descriptive frameworks characterize or describe KM. To date, the majority of frameworks presented in the literature are prescriptive.

Many researchers have tried to review the KM frameworks that have been presented in the literature, to compare and analyze them, as well as to give general directions on what a KM Framework should include and in what order. Reviewing the literature, the main and general accepted finding is that a codified, universally accepted framework has not been established for $\mathrm{KM}$ [58, 48, 71, 72]. In Figure 2 we illustrate the main streams of disagreements, regarding the KM frameworks.

The disagreement regarding the elements of a KM framework is the most important. The prescriptive frameworks tend to prescribe different tasks necessary for the implementation of KM. In the descriptive frameworks, there is also confusion about what should be included in a KM framework. Although someone can find some commonalities among the frameworks, a brief review can reveal the variations that exist between them [40]. This disagreement is the main reason that many research efforts are orientated towards the direction to standardize what a KM framework should contain [73-74].

The disagreement on the ordering or structuring of KM frameworks is also important. This concerns mainly the prescriptive frameworks, since they usually include some tasks which must be followed in a particular flow. The finding of the review is

Fig. 2: Major streams of disagreements for KM frameworks

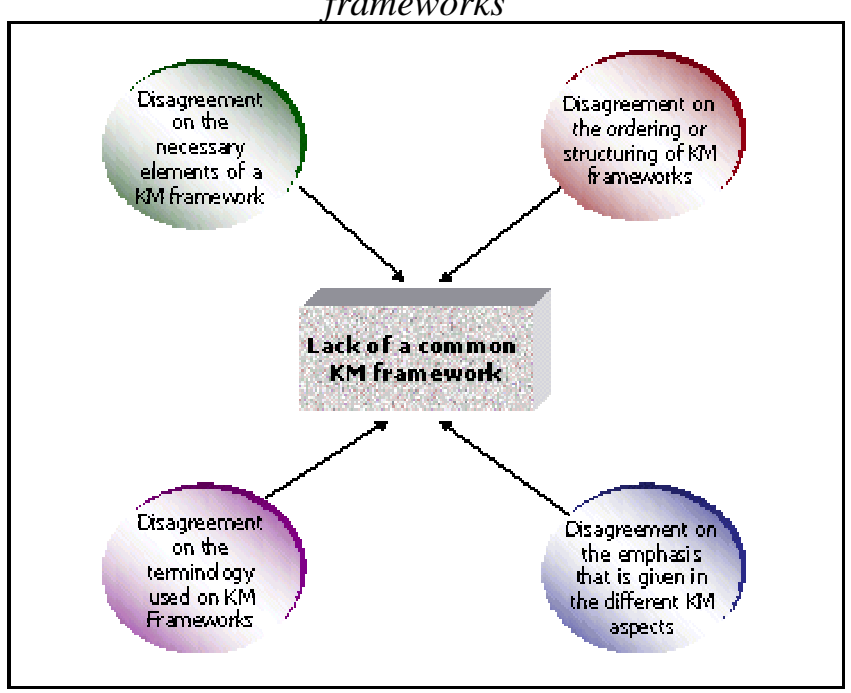


that, in many cases, the same elements can be found on the opposite order, in different frameworks [48]. Moreover, in many cases different KM frameworks include the same elements, but different terms are used for the same (or similar) activities or processes [75-78]. This inconsistency, regarding the used terminology, is a phenomenon that is common in other $\mathrm{KM}$ aspects also and it is considered among the most relevant issues for standardization $[58,79]$. Finally, the KM frameworks presented in the literature tend to emphasize different aspects of KM. The majority of KM frameworks do not address in an equal way the technical (technology, organizational structures) as well as the non technical (culture, human resources management) aspects. For example, many of the KM frameworks focus only on the knowledge cycle process or tasks, and consequently, other critical elements of $\mathrm{KM}$ such as integration of $\mathrm{KM}$ with the strategic goals of the organization, the people involved in KM activities, and the cultural context within which KM is developed are neglected $[48,80]$.

\subsection{IT: Is the centre of interest in KM?}

Information technology holds a pivotal position both as a domain for knowledge possession and creation and as a possible contributor to the knowledge proliferation and management processes. Figure 3 presents various technologies and knowledge types used in KM. Recently, many authors have argued that IT-supported KM systems are an important value-adding component of KM initiatives [81-84].
Modern technology may ease the integration of dispersed knowledge, speed up the replication of best practices across time and place, facilitate leveraging across uses and users to achieve economies of scale and scope. However, there is strong disagreement among researchers/practitioners on whether IT should be the center of interest in future research [85-86]. As Prusak [87] states:

Although IT is a wonderful facilitator of knowledge transmission, distribution and storage, it can never substitute for the rich inter-activity, communication, and learning that is inherent in dialogue.

In addition, while potential benefits of IT-supported KM systems have been addressed theoretically in the literature less is known about how these can be realized in practice.

\subsection{AI role in $\mathrm{KM}$}

Of particular interest, within the context of technology's role in $\mathrm{KM}$, is the potential role of Artificial Intelligence (AI) in its various forms and many arguments on the strengths and weaknesses of this technology have been presented by various researchers [88-90].

Reviewing the literature $[41,50,39]$ it becomes clear that the key research issue - resulting from researchers' disagreements - is (or should be) the development of an integrated framework for the use of AI technologies in various $\mathrm{KM}$ processes. Another research challenge is to assess the level of AI currently employed in $\mathrm{KM}$ applications in a qualitative way.

Fig. 3: Technologies and knowledge types in KM

Data

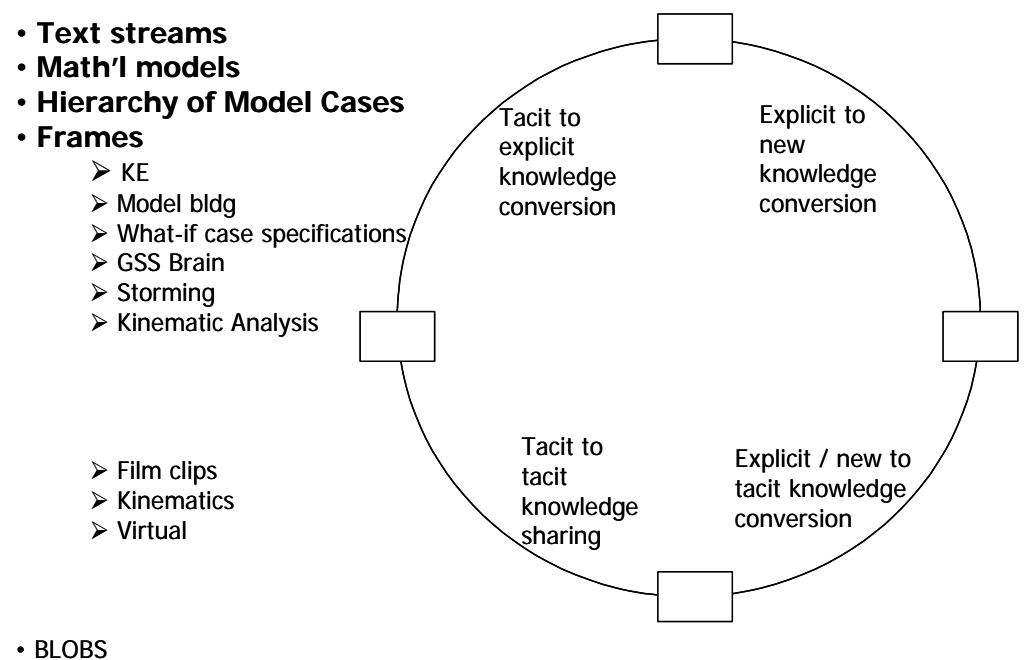

Data Types

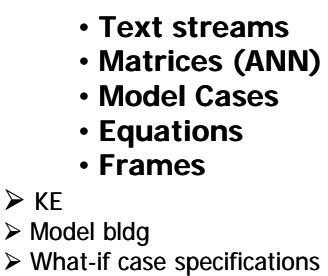

- Text streams 
While it is clearly important to recognize the limitations of these technologies - especially with respect to the management of tacit knowledge -, it is sure that they can play a supporting role in $\mathrm{KM}$ processes.

\subsection{Can knowledge be managed?}

Knowledge has the highest value, the most human contribution, the greatest relevance to decisions and actions, and the greatest dependence on a specific situation or context. It is also the most difficult of content types to manage, because it originates and is applied in the minds of human beings. So, the question which remains still valid is the following: "Can knowledge be managed in real practice?"

In rapidly changing and increasingly complex working arrangements, new knowledge is continuously being created, re-defined as well as being distorted. In this complex environment, it is still questionable as to what is being managed or as to whether knowledge can be managed. It can be argued that $\mathrm{KM}$ is not about managing knowledge but about changing entire business cultures and strategies of organizations to ones that value learning and sharing. Although some aspects of knowledge, as culture, organizational structure, communication processes and information can be managed, knowledge itself, arguably, cannot [53]. Reviewing KM literature in depth, the conclusion that one can manage or support processes of learning rather than managing knowledge is discussable. Winter [2] argues that skills may be taught through initiative learning, through trial and error and performance critique by the experienced mentor, rather than through knowledge fully conveyed by communication alone.

\section{Conclusions \& Recommended Directions for Research}

Globalization has placed businesses everywhere in new and different competitive situations where knowledgeable and effective behavior has come to provide the competitive edge. Nowadays, many organizations try to improve their competitive position through better use of knowledge, looking for new ways to harness and enhance the expertise and intellectual capital they possess, while aiming to continuously leverage them into new applied knowledge.

This paper explores the world of KM in a different way, by reviewing the current status quo and analyzing the main agreements and disagreements among researchers and practitioners in order to highlight the key issues, which need to be further researched. As it became clear, the KM debate emerged from an individual-knowledge focus in the 1970 s and 1980s to a group-knowledge focus in the 1990s and 2000s. Based on the key agreements among researchers and practitioners and having in mind the remaining disagreements, the third KM generation should proceed to further investigation of several KM issues and to further research. Recommended directions for further action research are the following:

$\checkmark$ Development of criteria for evaluating KM frameworks;

$\checkmark$ Development of systems for measuring the valuable knowledge, intellectual capital and other "intangible" assets of a corporation;

$\checkmark$ Inclusion of double-loop learning as part of a KM framework;

$\checkmark$ Study and analysis of investments and costs of IT supported KM systems in today's companies, and especially in SMEs;

$\checkmark$ Use of modern technologies as tools for transfer of explicit knowledge across cross-functional boundaries or silos of knowledge in organizations;

$\checkmark \quad$ The application of KM concept to other areas of our social life (health, public administration, higher education, etc.).

Finally, we should stress the fact that this literature review highlights the need to better clarify what we mean when we are using concepts such as "knowledge" and "KM" and to illustrate the differences between "competitive intelligence", "intellectual capital" and "KM".

References:

[1] Foucault, M., Power/Knowledge, Pantheon, New York, NY., 1980.

[2] Winter, S., Knowledge and competence as strategic assets, in Teece, D.J. (Ed.), The Competitive Challenge: Strategies for Individual Innovation and Renewal, Ballinger, Cambridge, MA, pp. 159-184, 1987.

[3] Leonard, D., Wellsprings of Knowledge Building and Sustaining the Sources of Innovation, Harvard Business School Press, Boston, MA., 1999.

[4] Wiig, K., Knowledge management foundations: Thinking about thinking-how people and organizations create, represent 
and use knowledge, Arlington, TX: Schema Press, 1993.

[5] Bhatt, G., Knowledge management in organizations: examining the interaction between technologies, techniques and people, Journal of Knowledge Management, Vol. 5, No.1, 2001, pp. 68-75.

[6] Metaxiotis, K., Psarras, J. and Papastefanatos, S., Knowledge and information management in e-learning environments: the user agent architecture, Information Management \& Computer Security, Vol. 10, No. 4, 2002, pp. 165-170.

[7] Davenport, T. and Prusak, L., Working Knowledge: Managing What Your Organisation Knows, Harvard Business School Press, Boston, MA., 1998.

[8] Liebowitz, J., Building Organizational Intelligence: A Knowledge Management Primer, CRC Press, Boca Raton, FL., 2000.

[9] Wild, R., Griggs, K. and Downing, T., A framework for e-learning as a tool for knowledge management, Industrial Management \& Data Systems, Vol. 102, No.7, 2002, pp. 371-380.

[10] Liebowitz, J. and Beckman, T., Knowledge Organizations: What every Manager Should Know, St. Lucie/CRC Press, Boca Raton, FL, 1998.

[11] Chauvel, D. and Despres, C., A review of survey research in knowledge management: 1997-2001, Journal of Knowledge Management, Vol.6, No.3, 2002, pp. 207-223.

[12] Moffett, S., McAdam, R. and Parkinson, S., An empirical analysis of knowledge management applications, Journal of Knowledge Management, Vol.7, No.3, 2003, pp. 6-26.

[13] Hayek, F., The uses of knowledge in society, American Economic Review, Vol. 35, 1945, pp. 1-18.

[14] Bell, D., The Cultural Contradiction of Capitalism, Heinemann, London, 1978.

[15] Marshall, A., Principles of Economics, Macmillan, London, 1965.

[16] Kuhn, T., The Structure of Scientific Revolutions, $2^{\text {nd }}$. Ed., University of Chicago Press, Chicago, IL., 1970.

[17] Habermas, J., Knowledge and Human Interests, Heinemann, London, 1972.

[18] Senge, P., The Fifth Discipline: The Art and Practice of the Learning Organisation, Doubleday, New York, NY., 1990.

[19] Nonaka, I., A dynamic theory of organizational knowledge creation,
Organization Science, Vol. 5, 1994, pp. 1437.

[20] Quinn, J., Intelligent Enterprise: A Knowledge and Service Based Paradigm for Industry, New York: The Free Press, 1992.

[21] Wiig, K., Knowledge Management Foundations, Schema Press, Arlington, TX., 1993.

[22] Mui, G. and McCarthy, W., FSA: Applying AI techniques to the familiarization phase of financial decision making, IEEE Expert, Vol. 2, 1987, pp. 33-41.

[23] Levine, P. and Pomerol, J., Knowledge representation by schemata in financial expert systems, Theory and Decision, Vol. 27, 1989, pp. 147-161.

[24] Ignizio, J.P., Introduction to Expert Systems, McGraw-Hill Inc., USA, 1991.

[25] Fowler, A., The role of AI-based technology in support of the knowledge management value activity cycle Journal of Strategic Information Systems, Vol. 9, 2000, pp. 107128.

[26] Grant, R., The knowledge based view of the firm: implications for management practice, Long Range Planning, Vol.30, No.3, 1997, pp. 450-455.

[27] Thierauf, R., Knowledge Management Systems for Business, Quorum Books, Westport, CT, 1999.

[28] McAdam, R. and Reid, R., SME and large organization perceptions of knowledge management: comparisons and contrasts, Journal of Knowledge Management, Vol. 5, 2001, No.3, pp. 231-241.

[29] Alavi, M. and Leidner, D., Knowledge management systems: issues, challenges and benefits, Communications of the Association for Information Systems, Vol. 1, No.7, 1999.

[30] Hasan, H. and Gould, E., Activity-based knowledge management systems, Journal of Information \& Knowledge Management, Vol.2, No.2, 2003, pp. 107-115.

[31] Lan Sia, C. and Al-Hawamdeh, Taxonomybuilding tools: An Investigative Study, Journal of Information \& Knowledge Management, Vol.2, No.1, 2003, pp. 63-77.

[32] Holsapple, C. and Joshi, K., Knowledge management: A three-fold framework, Kentucky Initiative for Knowledge Management, paper No.104, 1997.

[33] Rubenstein-Montano, B., Liebowitz, J., Buchwalter, J., McCaw, D., Newman, B. and Rebeck, K., A systems thinking framework for knowledge management, Decision 
Support Systems, Vol. 31, No.1, 2001, pp. 516.

[34] Chua, A., A framework for knowledge management implementation, Journal of Information \& Knowledge Management, Vol.2, No.1, 2003, pp. 79-86.

[35] Maier, R. and Remus, U., Implementing process-oriented knowledge management strategies, Journal of Knowledge Management, Vol.7, No.4, 2003, pp. 62-74.

[36] Rajan, A., Lank, E. and Chapple, K., Good practices in knowledge creation and exchange, Focus Central London, 1999.

[37] Pervan, G. and Ellison, R., Knowledge management practices and attitudes of IT departments: Do they practice what they preach?, Journal of Information \& Knowledge Management, Vol.2, No.1, 2003, pp. 15-31.

[38] Carneiro, A., The role of intelligent resources in knowledge management, Journal of Knowledge Management, Vol.5, No.4, 2001, pp. 358-367.

[39] Nemati, H., Steiger, D., Iyer, L. and Herschel, R., Knowledge warehouse: an architectural integration of knowledge management, decision support, artificial intelligence and data warehousing, Decision Support Systems, Vol. 33, 2002, pp. 143-161.

[40] Liao, S., Knowledge management technologies and applications - literature review from 1995 to 2002, Expert Systems with Applications, Vol. 25, 2003, pp. 155164.

[41] Metaxiotis, K., Ergazakis, K., Samouilidis, E. and Psarras, J., Decision support through knowledge management: the role of the artificial intelligence, International Journal of Computer Applications in Technology, (accepted paper, under publication).

[42] Wiig, K., New generation knowledge management: What may we expect?, Knowledge Research Institute, Inc., 2002

[43] Paraponaris, C., Third generation R\&D and strategies for knowledge management, Journal of Knowledge Management, Vol. 7, No.5, 2003, pp. 96-106.

[44] Polyani, M., Personal knowledge: Towards a Post-Critical Philosophy, University of Chicago Press, Chicago, IL, 1966.

[45] Nonaka, I. and Takeuchi, H., The KnowledgeCreating Company, Oxford University Press, Oxford, 1995.

[46] Tsoukas, H., The firm as a distributed knowledge system: a constructionist approach, Strategic Management Journal, Vol. 17, No.1, 1996, pp. 11-25.

[47] Liebowitz, J., The Knowledge Management Handbook, CRC Press, Boca Raton, FL, 1999.

[48] Rubenstein-Montano, B., Liebowitz, J., Buchwalter, J., McGaw, D., Newman, B. and Rebeck, K., SMARTVision: a knowledgemanagement methodology, Journal of Knowledge Management, Vol. 5, 2001, No. 4, pp. 300-310.

[49] Davenport, T., DeLong, D. and Beers, M., Successful knowledge management projects, Sloan Management Review, Vol. 39, 1998, No. 2, pp. 43-57.

[50] Liebowitz, J., Knowledge management and its links to artificial intelligence, Expert Systems With Applications, Vol. 20, 2001, pp. 1-6.

[51] Courtney, J., Decision making and knowledge management in inquiring organizations: toward a new decision-making paradigm for DSS, Decision Support Systems, Vol. 31, 2001, No.1, pp.17-38.

[52] Bolloju, N., Khalifa, M. and Turban, E., Integrating knowledge management into enterprise environments for the next generation decision support, Decision Support Systems, Vol. 33, 2002, pp. 163-176.

[53] Kakabadse, N., Kakabadse, A. and Kouzmin, A., Reviewing the knowledge management literature: towards a taxonomy, Journal of Knowledge Management, Vol. 7, 2003, No.4, pp. 75-91.

[54] Tyndale, P., A taxonomy of knowledge management software tools: origins and applications, Evaluation and Program Planning, Vol. 25, 2002, pp. 183-190.

[55] Wickert, A. and Herschel, R., Knowledgemanagement issues for smaller businesses, Journal of Knowledge Management, Vol. 5, No.4, 2001, pp. 329-337.

[56] Rowley, J., Is higher education ready for knowledge management?, The International Journal of Educational Management, Vol. 14, No.7, 2000, pp. 325-333.

[57] Metaxiotis, K. and Psarras, J., Applying Knowledge Management in Higher Education: The Creation of a Learning Organisation, Journal of Information and Knowledge Management, Vol. 2, No.4, 2003, pp. 1-7.

[58] Weber, F., Wunram, M., Kemp, J., Pudlatz, M. and Bredehorst, B., Standardisation in Knowledge Management - Towards a 
Common KM Framework in Europe, Proceedings of UNICOM Seminar "Towards Common Approaches \& Standards in KM", London, 2002.

[59] De Jarnett, L., Knowledge the latest thing, Information Strategy, The Executives Journal, Vol. 12, 1996, pp. 3-5.

[60] Quintas, P., Lefrere, P. and Jones, G., Knowledge management: a strategic agenda, Journal of Long Range Planning, Vol. 30, No.3, 1997, pp. 385-391.

[61] Choo, C., The knowing organization: how organizations use information to construct meaning, create knowledge and make decisions, International Journal of Information Management, Vol. 16, No.5, 1996.

[62] Ernst \& Young, Innovation in action - selling knowledge on the net, Perspectives on

Business Innovation - Managing

Organizational Knowledge, http://www.businessinnovation.ey.com/journa 1/features/whykno/body.html, 1997.

[63] Henry, J. and Walker, D., Managing Innovation, Sage, London, 1991.

[64] Demarest, M., Understanding knowledge management, Journal of Long Range Planning, Vol.30, No. 3, 1997, pp. 374-384.

[65] Holsapple, C.W., Joshi, K.D., An investigation of factors that influence the management of knowledge in organizations, Journal of Strategic Information Systems, Vol. 9, 2000, pp. 235-261.

[66] Holsapple, C. and Joshi, K., Knowledge management: A three-fold framework, Kentucky Initiative for Knowledge Management, paper No.104, 1997.

[67] Ruggles, R., Tools for knowledge management: An introduction, ButterworthHeinemann, Boston, 1997.

[68] O'Dell, C., A current review of knowledge management best practices, Conference on Knowledge Management and the Transfer of Best Practices, Business Intelligence, London, 1996.

[69] Argyris, C. and Schon, D., Organizational learning: A theory of action perspective, Addison-Wesley, Reading, MA., 1978.

[70] Holsapple, C.W., Joshi, K.D., Description and Analysis of Existing Knowledge Management Frameworks, Proceedings of the $32^{\text {nd }}$ Hawaii International Conference on System Sciences, 1999.

[71] Maier, R., Remus, U., Implementing processoriented knowledge management strategies,
Journal of Knowledge Management, Vol. 7, No. 4, 2003, pp. 62-74.

[72] Beckman, T., Knowledge Management Seminar Notes, ITESM, Monterrey, Mexico, 1998.

[73] European KM Forum, IST Project No 200026393.

[74] Holsapple, C.W., Joshi, K.D., Knowledge manipulation activities: results of a Delphi study, Information \& Management, Vol. 39, 2002, pp. 477-490.

[75] Liebowitz, J., Megbolugbe, I., A set of frameworks to aid the project manager in conceptualizing and implementing knowledge management initiatives, International Journal of Project Management, Vol. 21, 2003, pp. 189-198.

[76] Apostolou, D. and Mentzas, G., Managing corporate knowledge: a comparative analysis of experiences in consulting firms, $2^{\text {nd }}$ International Conference on Practical Aspects of Knowledge Management, Basel, Switzerland, 29-30 October 1998.

[77] Andersen Consulting, Collaboration and Knowledge Management, http://www.ac.com:80/services/knowledge/k m home.html, 2000.

[78] Lytras, M.D., Pouloudi, A., Project management as a knowledge management primer: the learning infrastructure in knowledge-intensive organizations: projects as knowledge transformations and beyond, The Learning Organisation, Vol. 10, No. 4, 2003, pp. 237-250.

[79] Ergazakis, K., Karnezis, K., Metaxiotis, K., Psarras, I., Knowledge Management in Enterprises: A Research Agenda, International Journal of Intelligent Systems in Accounting, Finance \& Management (accepted paper, under publication)

[80] Davenport, T., The Fad That Forgot People, Fast Company Magazine 1, http://www.fastcompany.com/online/01/reeng in.html, 1995.

[81] Lindvall, K., Rus, I. and Sinha, S., Software systems support for knowledge management, Journal of Knowledge Management, Vol.7, No.5, 2003, pp. 137-150.

[82] Tsoi, S., Cheung, C. and Lee, W., Knowledge-based customization of enterprise applications, Expert Systems with Applications, Vol.25, No.1, 2003, pp. 123132. 
[83] Edenius, M. and Borgerson, J., To manage knowledge by intranet, Journal of Knowledge Management, Vol.7, No.5, 2003, pp. 124-136.

[84] Gottschalk, P. and Khandelwal, V., Determinants of knowledge management technology projects in Australian law firms, Journal of Knowledge Management, Vol.7, No.4, 2003, pp. 92-105.

[85] Cook, S. and Yanow, D., Culture and organizational learning, Journal of Management Inquiry, Vol.2, No.4, 1993, pp. 373-390.

[86] Von Krogh, G., Ochijo, K. and Nonaka, I., Enabling knowledge creation, Oxford University Press, UK, 2000.
[87] Prusak, L., The eleven deadliest sins of knowledge management, ButterworthHeinemann, Boston, 1998.

[88] Turban, E., Decision support systems and intelligent systems, Prentice-Hall International, London, 1998.

[89] Darlington, K., The essence of expert systems, Prentice-Hall International, London, 1999.

[90] Wagner, G., Foundations of knowledge systems: With applications to databases and agents, Kluwer Academic, Boston, 1998. 